\title{
Genetic Variants of the Renin Angiotensin System: Effects on Atherosclerosis in Experimental Models and Humans
}

\author{
Alan Daugherty • Aruna Poduri • Xiaofeng Chen • \\ Hong Lu • Lisa A. Cassis
}

Published online: 31 March 2010

(C) The Author(s) 2010. This article is published with open access at Springerlink.com

\begin{abstract}
The renin angiotensin system (RAS) has profound effects on atherosclerosis development in animal models, which is partially complimented by evidence in the human disease. Although angiotensin II was considered to be the principal effector of the RAS, a broader array of bioactive angiotensin peptides have been identified that have increased the scope of enzymes and receptors in the RAS. Genetic interruption of the synthesis of these peptides has not been extensively performed in experimental or human studies. A few studies demonstrate that interruption of a component of the angiotensin peptide synthesis pathway reduces experimental lesion formation. The evidence in human studies has not been consistent. Conversely, genetic manipulation of the RAS receptors has demonstrated that AT1a receptors are profoundly involved in experimental atherosclerosis. Few studies have reported links of genetic variants of angiotensin II receptors to human atherosclerotic diseases. Further genetic studies are needed to define the role of RAS in atherosclerosis.
\end{abstract}

Keywords Renin angiotensin - Genetic variants ·

Atherosclerosis

\section{Introduction}

The development of atherosclerotic lesions is a chronic disease that proceeds through complex biochemical and cellular changes [1]. The proposed mechanistic basis for many of the events in the initiation and maturation phases

A. Daugherty $(\triangle) \cdot$ A. Poduri $\cdot \mathrm{X}$. Chen $\cdot \mathrm{H}$. Lu $\cdot$ L. A. Cassis Saha Cardiovascular Research Center, University of Kentucky, BBSRB, Room B-243,

Lexington, KY 40536-0509, USA

e-mail: Alan.Daugherty@uky.edu of lesion formation has involved aberrant metabolism of cholesterol transport. Indeed, we now have several decades of evidence that dysfunctional cholesterol metabolism is a major determinant of lesion development. However, more recently, substantial data have accumulated using genetic and pharmacologic approaches demonstrating a profound role for the renin angiotensin system (RAS) in experimental atherosclerosis. Although the RAS is a primary mediator of blood pressure and fluid balance, neither of these effects is the primary basis for the RAS to promote atherosclerosis. The consistent experimental literature has been complimented by a relatively uniform literature demonstrating a role for the RAS in human atherosclerotic disease.

The classical RAS synthesis pathway consists of a simple two-step enzymatic process in which angiotensinogen has 10 amino acids cleaved from the $\mathrm{N}$ terminus by renin and a subsequent removal of two further amino acids by angiotensin-converting enzyme (ACE) to yield the bioactive octapeptide, angiotensin II (AngII). Although the principal source of angiotensinogen, renin, and ACE have been the liver, kidneys, and lungs, respectively, there are evolving complexities of the location of these components. There is also a growing appreciation that other bioactive angiotensin peptides can be generated by more recently recognized RAS enzymes such as aminopeptidases and a homologue of ACE, termed ACE2. Therefore, it has now been defined that the RAS generates a range of bioactive peptides, some of which have direct antagonistic effects to each other $[2 \cdot \bullet]$.

The principal receptor mediating most of the described effects of AngII is the AT1 receptor, which is a seven transmembrane G protein-coupled receptor [3]. AT1 receptors are expressed in most major organs. There is a highly consistent literature regarding the role of AT1 receptors mediating many of the physiologic and pathologic effects 
of AngII. AT1 receptors undergo a chromosomal duplication resulting in the expression of two closely related subtypes that have been termed "a" and "b" in rodents. These receptors have 96\% sequence similarity and are indistinguishable by pharmacologic approaches. The majority of the sequence variations between the subtypes are in the C-terminal intracellular region. Although poorly defined, sequence differences in these intracellular regions have the potential to mediate subtype-specific responses to AngII through complex signaling pathways [4••]. The predominance of AngII effects in rodents are via stimulation of ATla receptors, although effects such as aortic contractions appear to be AT1b receptor-dependent [5]. AngII also stimulates AT2 receptors that are frequently considered to antagonize the effects of AT1 receptor stimulation. AT2 receptors are highly expressed in fetal tissues, but the abundance of the receptor markedly declines after birth. Unlike AT1 receptors, the functional consequences of AngII stimulation of AT2 receptors have generated an inconsistent literature in which effects are generally modest.

In animal studies, the predominance of the studies to determine a link of the RAS to atherosclerosis has been performed using genetically engineered mice to change receptor expression. This has also been combined with bone marrow transplantation to elucidate the role of a specific AngII receptor on cells on atherosclerosis. The experimental studies have the advantage of being able to retrieve atherosclerotic tissues to enable a direct measurement of size and characteristics of lesions. Obviously, studies in humans are not able to directly interrogate atherosclerotic tissues. Although imaging modalities are improved, insightful approaches have not been applied to the genetics of the RAS in the human disease. Therefore, a caveat of comparing experimental to human studies is the latter predominantly use indirect end points of atherosclerosis-associated diseases such as acute myocardial infarction and stroke.

\section{Genetic Determinants of Angiotensin Peptide Biosynthesis on Atherosclerosis}

\section{Experimental Studies}

There are genetically engineered mice that manipulate many of the components of the classic RAS. These include deficiencies of angiotensinogen, renin, and ACE. Unfortunately, deficiency of any of these proteins leads to the generation of mice that have similar profound renal deficiencies. Many of the offspring die shortly after birth. However, the pups can be rescued by subcutaneous injection of saline in the first 14 days after birth. Following rescue at the early pup stage, mice with whole body deficiency of angiotensinogen, renin, or ACE have persis- tent kidney abnormalities and high urine output but have comparable life span as wild-type mice without any further intervention.

The genetic manipulations of the RAS in atherosclerosis have been performed in mice, most commonly in those that lack either apolipoprotein E (apoE) or low-density lipoprotein LDL receptors [6]. Currently, no atherosclerosis studies have been performed using mice with whole body deficiencies of angiotensinogen or renin. However, one study has used genetic deficiency of renin to determine the contribution of this enzyme activity in bone marrowderived cells to lesion development. Bone marrow-derived stem cells were harvested from renin -/- mice and repopulated into irradiated LDL receptor $-/$ - mice [7•]. LDL receptor -/- mice repopulated with renin -/- bone marrow-derived cells had dramatically reduced lesion size after 3 months of feeding a saturated fat-enriched diet, compared with those repopulated with strain-matched, agematched, and gender-matched cells that were wild-type for renin. There was no indication that the absence of renin in bone marrow-derived cells had any effect on the activation status of the systemic RAS. The lack of effect on the systemic RAS in these studies suggests that bone marrowderived cells provide renin for local synthesis of angiotensin peptides within the artery in the development of atherosclerosis.

Initial studies investigated the role of ACE using heterozygous deficient mice bred into an apoE $+/$ - background [8]. No effects were noted on lesion size or on the chemical or cellular content of the lesions. A subsequent study used a variant named ACE.2, which expresses a soluble truncated form of the somatic form of the enzyme that is not cell tethered. Heterozygous ACE.2 (ACE +/2) mice on an apoE -/- background had greatly reduced atherosclerotic lesion size [9]. The authors were only able to generate two mice that were homozygous (ACE 2/2) for the ACE. 2 variant, which anecdotally had profoundly reduced lesion size. A more recent study was able to generate sufficient numbers of ACE $2 / 2$ mice in an apoE -/background to enable a statistically meaningful experiment [10]. Weiss et al. [10] demonstrated that homozygous ACE. 2 mice had large reductions in atherosclerotic lesion size of apoE -/- mice fed either a normal-fat or a saturated fat-enriched diet. This group also studied atherosclerosis in apoE -/- mice carrying the ACE. 3 variant. This variant has ACE expression that is restricted to the liver and kidney, with which the mice have undetectable ACE expression in the aorta but normal blood pressure. However, ACE 3/3 mice did not show a reduction of atherosclerosis compared with wild-type controls. ACE protein has been detected in several cell types within experimental and human atherosclerotic lesions $[11,12]$. Therefore, although ACE is present in lesions, the authors concluded that the locally 
expressed enzyme was not an absolute requirement for atherosclerosis development.

Table 1 summarizes the effects of genetic manipulations of components of angiotensin synthesis on development of atherosclerosis in mice. There are many publications that have used pharmacologic inhibition of renin or ACE to demonstrate a role for these enzymes in the development of experimental atherosclerosis $[13,14]$. However, there is a paucity of studies using genetic manipulations of the enzymes involved in angiotensin peptide synthesis on atherosclerosis development. Given the adverse effect of the whole body deficiencies of these enzymes, this field would be greatly enhanced by the availability of conditional knockout mice for either of these enzymes or their unique precursor, angiotensinogen. The availability of such mice would permit cell-specific and temporally controlled genetic deficiencies to be induced without attendant renal defects. Such mice would provide insight into the origin of the angiotensin peptides in lesion formation.

\section{Human Studies}

Of the three major proteins involved in the synthesis of angiotensin peptides, angiotensinogen, renin, and ACE, genes encoding for angiotensinogen and ACE have been investigated extensively to link genetic determinants of the RAS to atherosclerotic diseases in humans. A large number of single nucleotide polymorphisms (SNPs) have been described in the angiotensinogen gene located on chromosome 1. The most studied is the angiotensinogen M235T polymorphism, which consists of a nucleotide substitution in exon 2 that leads to the replacement of methionine to threonine at position 235 in the amino acid sequence, which has been proposed as a candidate influencing the predisposition to atherosclerotic diseases in humans [15]. Although there have been studies to confirm this relationship [16], these have not been consistent [17, 18•].

The most frequently studied polymorphism of the ACE gene on chromosome 17 is the insertion/deletion (I/D). This polymorphism is based on the presence or absence of a 250-base pair element located within intron 16 [19].
Because the difference is present in an intronic sequence, it seems unlikely to have functional consequences. Rather, it was suggested that the I/D polymorphism has a linkage disequilibrium to a region controlling ACE expression. A strong association has been noted between the ACE I/D gene polymorphism and activity of this enzyme in both blood and tissues. The I/I genotype was initially proposed to be protective because it is associated with greatly reduced ACE activity (approximately half) compared with D/D carriers.

The association of the ACE I/D polymorphism with the atherosclerosis-based disease was initially based on a multicenter, case-controlled study [20]. Petrovic and Peterlin [21] summarized earlier studies that investigated the link between I/D polymorphism and atherosclerosis-based diseases. Although some earlier studies confirmed the association between ACE I/D polymorphism and coronary artery disease, the first prospective study on a large sample size $(n=3590)$ failed to show any association [22]. Since the reviews of Petrovic and Peterlin [21] and Sayed-Tabatabaei et al. [23], subsequent studies have not clarified the link between ACE polymorphisms and atherosclerotic-based diseases. More recent studies have focused on the potential for ACE polymorphisms to predict coronary artery disease or determine whether the information provides any benefit to optimize therapeutic strategies, but they have failed to quell the inconsistencies in the literature. Furthermore, a recent meta-analysis of 58 studies of ACE I/D polymorphism on the response to therapeutic approaches for coronary artery disease concluded that the identification of this polymorphism provided no benefit to define clinical decisions [24]. Overall, despite the large number of studies to define the association of ACE polymorphisms and coronary artery disease, the lack of consistency indicates that such information will have little general use in predicting the onset and severity of the disease or providing useful information to personalize therapies.

Although polymorphisms of a single component of the RAS have not generated consistently insightful data, more recent studies have provided evidence that a combination of genotype variants of the RAS genes may be a more powerful determinant of coronary artery diseases $[25,26]$.
Table 1 Effects of genetic manipulations of components of angiotensin peptide synthesis on development of atherosclerosis in mice

$A C E$ angiotensin-converting enzyme, $L D L$ low-density lipoprotein

\begin{tabular}{lllll}
\hline Manipulation & Model & Gender & Atherosclerosis effect & Study \\
\hline \multicolumn{2}{l}{ Whole body manipulation } & & & \\
ACE $+/-$ & apoE $+/-$ & Male and female & No effect & Krege et al. [8] \\
ACE $+/ 2$ & apoE -/- & Male & Decrease & Hayek et al. [9] \\
ACE $2 / 2$ & apoE -/- & Male & Decrease $(n=2)$ & Hayek et al. [9] \\
& & Decrease & Weiss et al. [10] \\
ACE 3/3 & apoE -/- & Male & No effect & Weiss et al. [10] \\
Bone marrow transplantation & & & Lu et al. [7•] \\
Renin -/- & LDL receptor -/- & Male & Decrease & \\
\hline
\end{tabular}




\section{Genetic Determinants of Angiotensin II Receptors on Atherosclerosis}

\section{Experimental Studies}

Because the predominance of AngII effects in mice appears to be mediated via AT1a receptors, most of the genetic studies have used mice that are depleted of this receptor (Table 2). There has been a great consistency in the marked reduction in atherosclerosis in AT1a receptor -/- mice that are hypercholesterolemic due to deficiency of either apoE or LDL receptors combined with diet enriched in saturated fat [11, 27-30]. AT1a receptor deficiency also completely attenuated atherosclerosis in LDL receptor -/- mice augmented by AngII infusion [31, 32]. Furthermore, AT1a receptor deficiency also reduced atherosclerosis in diabetic apoE -/- mice [33]. The reduced atherosclerosis in AT1a receptor deficient mice has been consistent across all reports, in both genders, at all ages studied, and in different vascular beds that have been studied. The atherosclerosis literature is replete with conflicting data for the effect of genetic manipulations. Therefore, the consistency of the literature on AT1a receptor deficiency reducing atherosclerosis is both unusual and noteworthy.

Because most of the atherosclerosis mouse models are generated by dysfunctional cholesterol metabolism, it is surprising that deletion of AT1a receptors has such a large and consistent effect on lesion reduction. The resolution of this apparent paradox may be that the hypercholesterolemic state is associated with a marked augmentation of the RAS in terms of circulating proteins involved in the synthesis and secretion of angiotensin peptides [11]. The protective effect of AT1a receptor deficiency has been associated with changes in several measurements, including decreased oxidant stress and metalloproteinase expression and enhanced endothelial function. However, it has not been defined if these changes are a cause or consequence of the decreased atherosclerosis [27, 29]. Blood pressure changes have also been inconsistent in hypercholesterolemic ATla receptordeficient mice [11, 27]. Nevertheless, blood pressure per se does not appear to be a major factor in the development of atherosclerosis in mouse models of the disease [13].

The effect of AT1a receptors on atherosclerosis has also been studied using bone marrow transplantation. It has primarily been used to define the role of AT1a receptor expression on leukocytes that infiltrate during lesion development, although this technique has the potential to also influence other cell types that originate from bone marrow. Unlike the uniform demonstration of whole body AT1a receptor deficiency decreasing atherosclerosis, the literature using bone marrow transplantation has produced

Table 2 Effects of genetic manipulations of angiotensin II receptors on development of atherosclerosis in mice

\begin{tabular}{|c|c|c|c|c|}
\hline $\begin{array}{l}\text { Receptor } \\
\text { deficiency }\end{array}$ & Model & Gender & Atherosclerosis effect & Study \\
\hline \multicolumn{5}{|c|}{ Whole body deficiency } \\
\hline \multirow[t]{6}{*}{ AT1a } & LDL receptor -/- & $\begin{array}{l}\text { Male and } \\
\text { female }\end{array}$ & Decrease & Daugherty et al. [11] \\
\hline & apoE -/- & Male & Decrease & Wassmann et al. [27] \\
\hline & & & Decrease & Li et al. [28] \\
\hline & & & Decrease & Tomono et al. [30] \\
\hline & & & Decrease & Eto et al. [29] \\
\hline & Diabetic apoE-/- & & Decrease & Ihara et al. [33] \\
\hline \multirow[t]{4}{*}{ AT2 } & LDL receptor -/- & $\begin{array}{l}\text { Male and } \\
\text { female }\end{array}$ & No effect & Daugherty et al. [11] \\
\hline & apoE-/- & Male & Increase & Iwai et al. [39] \\
\hline & & & No effect on size, but composition change & Sales et al. [38] \\
\hline & Diabetic apoE-/- & & Decrease & Koitka et al. [37] \\
\hline \multicolumn{5}{|c|}{ Bone marrow transplantation } \\
\hline \multirow[t]{6}{*}{ AT1a } & $\begin{array}{l}\text { LDL receptor -/-; AngII } \\
\text { infused }\end{array}$ & Male & No effect in AT1aR -/-; modest decrease in $+/+$ & Cassis et al. [31] \\
\hline & apoE -/-; AngII infused & & No effect in AT1aR -/-; modest decrease in $+/+$ & Koga et al. [35] \\
\hline & LDL receptor -/- & & No effect & Lu et al. $[7 \cdot]$ \\
\hline & apoE -/- & & Decrease & Fukuda et al. [32] \\
\hline & & & Decrease & $\begin{array}{l}\text { Tsubakimoto et al. } \\
\text { [34] }\end{array}$ \\
\hline & & & Increase & Kato et al. [36] \\
\hline
\end{tabular}

AngII angiotensin II, apoE apolipoprotein E, $L D L$ low-density lipoprotein 
inconsistent results. AT1a receptor deficiency in bone marrow-derived cells has been demonstrated to attenuate $[32,34]$, have no effect $[7,31,35]$, or increase atherosclerosis [36] in hypercholesterolemic mice, either induced by hypercholesterolemia alone or augmented with AngII infusion. The basis for this inconsistency is not readily apparent. Another approach to determine the role of the AT1a receptor expression in specific cell types is the use of Cre-lox technology to develop deficiencies that can be both cell specific and inducible at specific time intervals. However, there are currently no reports that have used conditional genetic deficiencies of ATla receptors to define the cellular components that are stimulated by AngII or hypercholesterolemia to augment atherosclerosis.

As described above, AngII stimulation of AT2 receptors is commonly considered to exert opposite effects to AngII stimulation of AT1 receptors. Contrary to the consistent reductions of atherosclerosis in AT1a receptor-deficient mice, genetically engineered deficiency of AT2 receptors has generated a range of responses. The changes of atherosclerosis in hypercholesterolemic AT2 receptor-deficient mice cover the entire spectrum of decreases [37], no effect [11], no effect on size but changes in composition [38], or increases [39] in lesion formation.

Overall, the effects of the genetically engineered whole body deficiency of ATla receptors have been both striking in the magnitude of the effects and consistent in reports from many laboratories. This contrasts sharply with the literature to define the cellular location of the AT1a receptors involved in the development of atherosclerosis. It also contrasts sharply with genetic studies on AT2 receptors. There is no obvious explanation for this inconsistent literature.

\section{Human Studies}

The relevance of angiotensin receptors in atherosclerosis has been observed in humans in a limited number of gene association human studies. As noted above, the AT1 receptor located on chromosome 3 is thought to mediate most of the effects of AngII [40]. One of the most common genetic variants is the A1166C SNP located in the 3' UTR region of the AT1 receptor gene. The CC mutant genotype has been associated with increased risk of myocardial infarction, coronary artery stenosis, and carotid atherosclerosis [41, 42]. This polymorphism was also associated with increased total plasma cholesterol concentrations and influenced the risk for essential hypertension [43]. In Chinese men, the combined effects of all functional genetic variants present in this gene were associated with increased risk of myocardial infarction [44]. In addition, combination of genetic variants of ACE I/D along with AT1 receptor A1166C polymorphism have been predicted as powerful determinants for atherosclerosis. Conversely, numerous studies have also demonstrated no association of this polymorphism with atherosclerosis [45-47]. Another polymorphism in exon 5 of the AT1 receptor gene, which is conversion of C to $\mathrm{T}$ at 537 position, has been found to be not associated with atherosclerosis [48].

The AT2 receptor gene is located on the X chromosome. A common polymorphism of AT2 receptors, $-1332 \mathrm{G} / \mathrm{A}$, is present in the promoter region but has not been found to be associated with premature coronary artery disease [49]. Recently, another polymorphism in the AT2 receptor gene has been reported, which is A1675G located in intron 1 . This genetic variant has been associated with the increased severity of atherosclerosis, especially in hypertensive males [50]. Collectively, there have been inconsistent reports obtained from population-based studies. As with the gene association studies in proteins of angiotensin peptide synthesis, they have yielded relatively little to providing insight into the pathology of atherosclerosis.

\section{Conclusions}

The role of the RAS has been explored extensively in experimental atherosclerosis using pharmacologic and genetic approaches. Although the literature is unusually consistent in defining a role of the RAS in atherosclerosis, specific mechanistic insights are missing or inconsistent. Genetic approaches would be the most definitive approach to the elucidation of these deficiencies of information. Unlike the experimental studies, there is scant information of the role of genetic determinants of the RAS in human atherosclerotic-associated diseases.

Acknowledgments The authors' work in this area is supported by the National Institutes of Health (HL62846). We also acknowledge the editorial assistance of Debra L. Rateri.

Disclosure No potential conflicts of interest relevant to this article were reported.

Open Access This article is distributed under the terms of the Creative Commons Attribution Noncommercial License which permits any noncommercial use, distribution, and reproduction in any medium, provided the original author(s) and source are credited.

\section{References}

Papers of particular interest, published recently, have been highlighted as:

- Of importance

•• Of major importance

1. Rader DJ, Daugherty A: Translating molecular discoveries into new therapies for atherosclerosis. Nature 2008, 451:904-913. 
2. • Le TH, Coffman TM: Targeting genes in the renin-angiotensin system. Curr Opin Nephrol Hypertens 2008, 17:57-63. This is a comprehensive review of the insight that genetic manipulations of the RAS genes have provided to physiologic and pathophysiologic processes.

3. Elton TS, Martin MM: Angiotensin II type 1 receptor gene regulation: transcriptional and posttranscriptional mechanisms. Hypertension 2007, 49:953-961.

4. - Mehta PK, Griendling KK: Angiotensin II cell signaling: physiological and pathological effects in the cardiovascular system. Am J Physiol Cell Physiol 2007, 292:C82-97. This is a clear description, in text and graphic forms, of the many complexities of AngII-stimulated intracellular signaling molecules.

5. Zhou Y, Chen Y, Dirksen WP, et al.: AT1b receptor predominantly mediates contractions in major mouse blood vessels. Circ Res 2003, 93:1089-1094

6. Daugherty A: Mouse models of atherosclerosis. Am J Med Sci 2002, 323:3-10.

7. - Lu H, Rateri DL, Feldman DL, et al.: Renin inhibition reduces hypercholesterolemia-induced atherosclerosis in mice. $J$ Clin Invest 2008, 118:984-993. This is a demonstration that systemic renin inhibition and deficiency of the enzyme in bone marrowderived cells profoundly reduce experimental atherosclerosis.

8. Krege JH, Moyer JS, Langenbach LL, et al.: Angiotensinconverting enzyme gene and atherosclerosis. Arterioscler Thromb Vasc Biol 1997, 17:1245-1250.

9. Hayek T, Pavlotzky E, Hamoud S, et al.: Tissue angiotensinconverting- enzyme (ACE) deficiency leads to a reduction in oxidative stress and in atherosclerosis. Studies in ACE-knockout mice type 2. Arterioscler Thromb Vasc Biol 2003, 23:2090-2096.

10. Weiss D, Bernstein KE, Fuchs S, et al.: Vascular wall ACE is not required for atherogenesis in $\mathrm{ApoE}(-/-)$ mice. Atherosclerosis 2009 (in press).

11. Daugherty A, Rateri DL, Lu H, et al.: Hypercholesterolemia stimulates angiotensin peptide synthesis and contributes to atherosclerosis through the AT1A receptor. Circulation 2004, 110:3849-3857.

12. Diet F, Pratt RE, Berry GJ, et al.: Increased accumulation of tissue ACE in human atherosclerotic coronary artery disease. Circulation 1996, 94:2756-2767.

13. Lu H, Cassis LA, Daugherty A: Atherosclerosis and arterial blood pressure in mice. Curr Drug Targets 2007, 8:1181-1189.

14. Daugherty A, Lu H, Rateri DL, Cassis LA: Augmentation of the renin-angiotensin system by hypercholesterolemia promotes vascular diseases. Future Lipidol 2008, 3:625-636 .

15. Katsuya T, Koike G, Yee TW, et al.: Association of angiotensinogen gene T235 variant with increased risk of coronary heart disease. Lancet 1995, 345:1600-1603.

16. Rodriguez-Perez JC, Rodriguez-Esparragon F, HernandezPerera O, et al.: Association of angiotensinogen M235T and A (-6)G gene polymorphisms with coronary heart disease with independence of essential hypertension: the PROCAGENE study. Prospective Cardiac Gene. J Am Coll Cardiol 2001, 37:1536-1542.

17. Sethi AA, Nordestgaard BG, Gronholdt ML, et al.: Angiotensinogen single nucleotide polymorphisms, elevated blood pressure, and risk of cardiovascular disease. Hypertension 2003, 41:1202-1211.

18. - Zafarmand MH, van der Schouw YT, Grobbee DE, et al.: The M235T polymorphism in the AGT gene and CHD risk: evidence of a Hardy-Weinberg equilibrium violation and publication bias in a meta-analysis. PLoS One 2008, 3:e2533. This is a comprehensive analysis of many studies to define the weak association of a common functional angiotensinogen polymorphism with coronary heart disease.

19. Rigat B, Hubert C, Alhenc-Gelas F, et al.: An insertion/deletion polymorphism in the angiotensin I-converting enzyme gene accounting for half the variance of serum enzyme levels. $J$ Clin Invest 1990, 86:1343-1346.

20. Cambien F, Poirier O, Lecerf L, et al.: Deletion polymorphism in the gene for angiotensin-converting enzyme is a potent risk factor for myocardial infarction. Nature 1992, 359:641-644.

21. Petrovic D, Peterlin B: Pharmacogenomic considerations of the insertion/deletion gene polymorphism of the angiotensin Iconverting enzyme and coronary artery disease. Curr Vasc Pharmacol 2004, 2:271-279.

22. Lindpaintner K, Pfeffer MA, Kreutz R, et al.: A prospective evaluation of an angiotensin-converting-enzyme gene polymorphism and the risk of ischemic heart disease. N Engl J Med 1995, 332:706-711.

23. Sayed-Tabatabaei FA, Oostra BA, Isaacs A, et al.: ACE polymorphisms. Circ Res 2006, 98:1123-1133.

24. Kitsios G, Zintzaras E: ACE (I/D) polymorphism and response to treatment in coronary artery disease: a comprehensive database and meta-analysis involving study quality evaluation. BMC Med Genet 2009, 10:50.

25. Kretowski A, McFann K, Hokanson JE, et al.: Polymorphisms of the renin-angiotensin system genes predict progression of subclinical coronary atherosclerosis. Diabetes 2007, 56:863-871.

26. Tsai CT, Hwang JJ, Ritchie MD, et al.: Renin-angiotensin system gene polymorphisms and coronary artery disease in a large angiographic cohort: detection of high order gene-gene interaction. Atherosclerosis 2007, 195:172-180.

27. Wassmann S, Czech T, Van Eickels M, et al.: Inhibition of dietinduced atherosclerosis and endothelial dysfunction in apolipoprotein E/Angiotensin II type 1A receptor double-knockout mice. Circulation 2004, 110:3062-3067.

28. Li Z, Iwai M, Wu L, et al.: Fluvastatin enhances the inhibitory effects of a selective AT1 receptor blocker, valsartan, on atherosclerosis. Hypertension 2004, 44:758-763.

29. Eto H, Miyata M, Shirasawa T, et al.: The long-term effect of angiotensin II type 1a receptor deficiency on hypercholesterolemiainduced atherosclerosis. Hypertens Res 2008, 31:1631-1642.

30. Tomono Y, Iwai M, Inaba S, et al.: Blockade of AT(1) receptor improves adipocyte differentiation in atherosclerotic and diabetic models. Am J Hypertens 2008, 21:206-212.

31. Cassis LA, Rateri DL, Lu H, Daugherty A: Bone marrow transplantation reveals that recipient AT1a receptors are required to initiate angiotensin II-induced atherosclerosis and aneurysms. Arterioscler Thromb Vasc Biol 2007, 27:380-386.

32. Fukuda D, Sata M: Role of bone marrow renin-angiotensin system in the pathogenesis of atherosclerosis. Pharmacol Ther 2008, 118:268-276.

33. Ihara Y, Egashira K, Nakano K, et al.: Upregulation of the ligandRAGE pathway via the angiotensin II type I receptor is essential in the pathogenesis of diabetic atherosclerosis. $J$ Mol Cell Cardiol 2007, 43:455-464.

34. Tsubakimoto $\mathrm{Y}$, Yamada $\mathrm{H}$, Yokoi $\mathrm{H}$, et al.: Bone marrow angiotensin AT1 receptor regulates differentiation of monocyte lineage progenitors from hematopoietic stem cells. Arterioscler Thromb Vasc Biol 2009, 29:1529-1536.

35. Koga J, Egashira K, Matoba T, et al.: Essential role of angiotensin II type 1a receptors in the host vascular wall, but not the bone marrow, in the pathogenesis of angiotensin II-induced atherosclerosis. Hypertens Res 2008, 31:1791-1800.

36. Kato H, Ishida J, Nagano K, et al.: Deterioration of atherosclerosis in mice lacking angiotensin II type 1A receptor in bone marrowderived cells. Lab Invest 2008, 88:731-739.

37. Koitka A, Cao Z, Koh P, et al.: Angiotensin II subtype 2 receptor blockade and deficiency attenuate the development of atherosclerosis in an apolipoprotein E-deficient mouse model of diabetes. Diabetologia 2010, 53:584-592. 
38. Sales VL, Sukhova GK, Lopez-Ilasaca MA, et al.: Angiotensin type 2 receptor is expressed in murine atherosclerotic lesions and modulates lesion evolution. Circulation 2005, 112:3328-3336.

39. Iwai M, Chen R, Li Z, et al.: Deletion of angiotensin II type 2 receptor exaggerated atherosclerosis in apolipoprotein E-null mice. Circulation 2005,112:1636-1643.

40. Schiffrin EL, Touyz RM: Multiple actions of angiotensin II in hypertension: benefits of AT1 receptor blockade. J Am Coll Cardiol 2003, 42:911-913.

41. Fernandez-Arcas N, Dieguez-Lucena JL, Munoz-Moran E, et al.: The genotype interactions of methylenetetrahydrofolate reductase and renin-angiotensin system genes are associated with myocardial infarction. Atherosclerosis 1999, 145:293-300.

42. Zhu S, Meng QH: Association of angiotensin II type 1 receptor gene polymorphism with carotid atherosclerosis. Clin Chem Lab Med 2006, 44:282-284.

43. Morisawa $T$, Kishimoto $Y$, Kitano $M$ et al.: Influence of angiotensin II type 1 receptor polymorphism on hypertension in patients with hypercholesterolemia. Clin Chim Acta 2001, 304:91-97.

44. Su S, Chen J, Zhao J, et al.: Angiotensin II type I receptor gene and myocardial infarction: tagging SNPs and haplotype based association study. The Beijing atherosclerosis study. Pharmacogenetics 2004, 14:673-681.
45. Jeunemaitre X, Ledru F, Battaglia S, et al.: Genetic polymorphisms of the renin-angiotensin system and angiographic extent and severity of coronary artery disease: the CORGENE study. Hum Genet 1997, 99:66-73.

46. Gruchala M, Ciecwierz D, Ochman K et al.: Left ventricular size, mass and function in relation to angiotensin-converting enzyme gene and angiotensin-II type 1 receptor gene polymorphisms in patients with coronary artery disease. Clin Chem Lab Med 2003, 41:522-528.

47. Burdon KP, Langefeld CD, Beck SR, et al.: Association of genes of lipid metabolism with measures of subclinical cardiovascular disease in the Diabetes Heart Study. J Med Genet 2005, 42:720-724.

48. Schelleman H, Klungel $\mathrm{OH}$, Kromhout D, et al.: Prevalence and determinants of undertreatment of hypertension in the Netherlands. J Hum Hypertens 2004, 18:317-324.

49. Alfakih K, Brown B, Lawrance RA, et al.: Effect of a common $\mathrm{X}$-linked angiotensin II type 2-receptor gene polymorphism $(-1332 \mathrm{G} / \mathrm{A})$ on the occurrence of premature myocardial infarction and stenotic atherosclerosis requiring revascularization. Atherosclerosis 2007, 195: e32-38.

50. Tousoulis D, Koumallos N, Antoniades C, et al.: Genetic polymorphism on type 2 receptor of angiotensin II, modifies cardiovascular risk and systemic inflammation in hypertensive males. Am J Hypertens 2009 (in press). 